\title{
Physicochemical characterization of resistant starch type V (RS5) from manggu cassava starch (Manihot esculenta)
}

\author{
${ }^{1,2 *}$ Faridah, D.N., ${ }^{2}$ Andriani, I., ${ }^{3}$ Talitha Z.A. and ${ }^{1,2}$ Budi, F.S. \\ ${ }^{1}$ Departement of Food Science and Technology, Faculty of Agricultural Engineering and Technology, IPB \\ University, Indonesia \\ ${ }^{2}$ Southeast Asian Food and Agricultural Science and Technology (SEAFAST-Center), IPB University, \\ Bogor, Indonesia \\ ${ }^{3}$ Food Technology Program, Sumatera Institute of Technology, Lampung, Indonesia
}

\begin{abstract}
Article history:
Received: 7 September 2020

Received in revised form: 15

October 2020

Accepted: 30 November 2020

Available Online: 21 March 2021
\end{abstract}

\section{Keywords:}

Amylose-lipid complex, Resistant starch type 5 (RS5), Starch digestibility,

Tapioca starch modification

DOI:

https://doi.org/10.26656/fr.2017.5(2).496

\begin{abstract}
Resistant starch has been well known to have beneficial health effects, mainly for digestive tracts. Starch isolated from cassava showed characteristics required to produce resistant starch type 5 (RS5). In this study, we modified tapioca starch through the gelatinization process with the addition of palm oil, coconut oil, stearic acid and lauric acid with 3 treatments, i.e. concentration (1) $10 \%$, (2) $20 \%$ and (3) $30 \%$. The result of study showed that modification of starch can decrease starch digestibility, increase levels of resistant starch and lower amylose levels. The analysis using X-Ray diffraction, strearic acid $30 \%$ had the peak at $7.5^{\circ}, 22^{\circ}$ and $24^{\circ}$. Peak $7.5^{\circ}$ was a amylose-lipid complex as RS5. The profile of starch gelatinization using Rapid Visco Analyzer (RVA) showed that the addition of fatty acid can decrease the value of breakdown, setback, and peak viscosity. These results indicates modification of tapioca starch with fatty acid (stearic acid or lauric acid) can form amylose-lipid complex (RS5).
\end{abstract}

\section{Introduction}

Starch is a food source that has high availability and can be used as energy reserves in the form of glycogen in the human body. One type of starch that is widely used is cassava starch or tapioca. Cassava production in Indonesia reached 22 million tons in 2016 (Indonesia Ministry of Agriculture, 2016). One of the cassava varieties in Indonesia is the Manggu cassava variety which is a superior variety from Sukabumi Indonesia with a diameter of 4-5 cm (Carolina, 2009). The amount of amylose content in this cassava around $22.22 \%$ (Hartati and Hartati, 2019). Native starch has several deficiencies in physicochemical properties that can inhibit their application in industry, the modified starch techniques were used to produce resistant starch. Modification of starch can increase resistant starch that has functional properties that play a role in the processing, but also resistant to digestion (Kusnandar, 2011; Faridah, et al., 2019). One type of resistant starch is a type 5 or RS5 resistant starch which is a amyloselipid complex.

The formation of amylose-lipid complexes occurs during gelatinization and its influenced by several factors including chain length and type of fat bond (Aliasson and Krog, 1985), type of starch, water content, polymerization rate, the ratio of amylose to lipid concentration, manufacturing process, $\mathrm{pH}$ time and medium starches that contain high amylose will be more easily made complex (Obiro et al., 2012). RS5 has stable properties for processing and resistant to hydrolysis by amylase enzymes (Jane and Robyt, 1984), limiting swelling on starch granules and being resistant to heating (Birt et al., 2013). Amylose-lipid complex formations also affect the pasting properties of starch. Peak viscosity of corn starch decreased by complexing the amylose with lipid (Ai et al., 2013). RS5 has been applied as bread making ingredient that produced lower glycemic index value (Hasjim et al., 2010). Moreover, than that, RS5 has also been applied in bioactive nano-encapsulation production and as flavor ingredient (Obiro et al., 2012).

Starch modification for complexing amylose with lipid has been exhibited by Ai et al. (2013) using tapioca starch with $29 \%$ amylose content which could decrease enzymatic hydrolysis from $77.5 \%$ to $65.5 \%$ with stearic acid, also with palmitic acid (66.1\%), corn oil (66.4\%), oleic acid $(66.8 \%)$, soy lecithin $(69.5 \%)$ and linoleic acid $(72.0 \%)$ with $10 \%$ addition of these lipids from the dry 
weight of starch. The complex of amylose-lipid also applied in corn starch with $10 \%$ dry basis of oleic acid addition resulting in a peak temperature $(\mathrm{Tp}=$ $\left.102.2 \pm 0.0^{\circ} \mathrm{C}\right)$ and enthalpy changes $(\Delta \mathrm{H}=1.9 \pm 0.1 \mathrm{~J} / \mathrm{g})$ (Ai et al., 2013).

High availability of resources in Indonesia, including palm oil, coconut oil, stearic acid and lauric acid and also the high amount of amylose content in Manggu cassava may be used to modify starch into amylose lipid complex.

\section{Materials and methods}

\subsection{Materials}

Manggu type cassava 9-month originating from Cikarawang, Dramaga Bogor. Palm oil and coconut oil were obtained from a supermarket in Indonesia. The oil used is olein phase, obtained from Supermarket Bogor, stearic acid triple pressed (C16:0 58.29\%, C18:0 40.83\%), and lauric acid (C12: 0 99.55\%.

Other materials were glucose, aquadest, phenol, $\mathrm{H}_{2} \mathrm{SO}_{4}$ (Merck, Germany), KCL-HCL buffer, pepsin (Sigma P7000, USA), phosphate buffer, $\alpha$-amylase (Sigma 10065, USA), KOH (Merck, Germany), HCl (Merck, Germany), amyloglucosidase (Sigma A7095, USA), $\mathrm{NaOH}$ (Merck, Germany), glacial acetic acid, iodine.

\subsection{Preparation and starch modification}

Starch extraction can be done by the wet method based on Lingga et al. (1986). The process of starch modification for the formation of amylose lipid complex based on Ai et al. (2013). The process of modification of starch for the formation of a lipid amylose complex compound is carried out by weighing as much as $4.4 \mathrm{~g}$ of tapioca starch weighed into a $250 \mathrm{~mL}$ beaker glass, then added $10 \%$ lipid $(0.4 \mathrm{~g})$ or according to the concentration of lipid, and then added distillate water $12 \mathrm{~mL}$, heated in a water bath with a temperature of $95^{\circ} \mathrm{C}$ for 8 mins with constant stirring until the starch is perfectly gelatinized. The sterilized starch sample was stored on a baking sheet of alumunium to dry on a drying oven at a temperature of $50^{\circ} \mathrm{C}$ for $20 \mathrm{hrs}$. The modified starch has been dried and then mashed using a High-Speed Grinder (RT-02A 150G). Modified cassava using palm oil, coconut oil, stearic acid and lauric acid with 3 treatments, i.e. concentration (1) $10 \%$, (2) $20 \%$ and (3) $30 \%$ according to the research design (Table 1).

\subsubsection{Resistant starch content}

About $5 \mathrm{mg}$ of pure glucose was diluted in $50 \mathrm{~mL}$ aqua and diluted $(0,10,20,30,40,50,60 \mu \mathrm{g} / \mathrm{mL}$ glucose
Table 1. Modified tapioca starch design with oil and fatty acids

\begin{tabular}{lcc}
\hline $\begin{array}{c}\text { Treatment } \\
\text { Control }\end{array}$ & $\begin{array}{c}\text { Concentration }(\% \mathrm{w} / \mathrm{w}) \\
\text { Coconut Oil }\end{array}$ & $\begin{array}{c}\text { Code } \\
\end{array}$ \\
\hline 10 & MK 10 \\
\hline Palm Oil & 30 & MK 20 \\
& 10 & MK 30 \\
\hline Stearic Acid & 20 & MS 10 \\
& 30 & MS 20 \\
& 10 & MS 30 \\
\hline Lauric Acid & 20 & AS 10 \\
& 30 & AS 20 \\
& 10 & AS 30 \\
\hline
\end{tabular}

solution). Each concentration was moved into the reaction tube and $0.5 \mathrm{~mL}$ of phenol $5 \%$, was added and then mixed well with a vortex. Then, $2.5 \mathrm{~mL}$ of concentrated $\mathrm{H}_{2} \mathrm{SO}_{4}$ was added quickly to each tube and aged for 10 mins. Each tube was aged once more for 20 mins in ambient temperature before measured in term of absorbance using spectrophotometer UV-Vis on $490 \mathrm{~nm}$. The results were used as a standard curve of resistant starch content.

The sample was prepared by mixing with KCL-HCL buffer $5 \mathrm{~mL}$ and $0.1 \mathrm{~mL}$ pepsin $(4000 \mathrm{U} / 10 \mathrm{~mL}$ buffer $\mathrm{KCl}-\mathrm{HCl}$ ) then incubated at $40^{\circ} \mathrm{C}$ for 60 mins using water bath shaker before cooled at ambient temperature. The sample was added with $4.5 \mathrm{~mL}$ phosphate buffer and $0.5 \mathrm{~mL} \alpha$-amylase $(15.2 \mathrm{mg} \alpha$-amylase $/ \mathrm{mL}$ phosphate buffer) incubated in $37^{\circ} \mathrm{C}$ for $16 \mathrm{hrs}$ using a water bath shaker, centrifuged (15 mins, $3000 \mathrm{rpm})$, then the precipitated sample was washed with $10 \mathrm{~mL}$ of aqua and added with $1.5 \mathrm{~mL} \mathrm{KOH}$ solution $4 \mathrm{M}$ before aged for 30 mins in ambient temperature. After aging, $2.75 \mathrm{~mL}$ of $\mathrm{HCl} 2 \mathrm{M}, 1.5 \mathrm{~mL}$ of sodium acetate buffer and $40 \mu \mathrm{L}$ amyloglucosidase was added, incubated in the water bath shaker for $45 \mathrm{mins}$ in $60^{\circ} \mathrm{C}$ before centrifuged $(15 \mathrm{mins}$ $3000 \mathrm{rpm})$ then the supernatant was contained and washed with $10 \mathrm{~mL}$ of aquadest. The supernatant was mixed with $0.5 \mathrm{~mL}$ of phenol $5 \%$, was added and then mixed well with a vortex. Then, $2.5 \mathrm{~mL}$ of concentrated $\mathrm{H}_{2} \mathrm{SO}_{4}$ was added quickly to each tube and aged for 10 mins. Each tube was aged once more for 20 mins in ambient temperature before measured in term of absorbance using spectrophotometer UV-Vis on $490 \mathrm{~nm}$.

\subsubsection{Starch digestibility}

Starch sample or potato starch $(0.1 \mathrm{~g})$ was added 10 $\mathrm{mL}$ of distilled water and heated in a water bath at $90^{\circ} \mathrm{C}$ for 15 mins or until gelatinized. The sample was 
removed and cooled under running water. The sample solution was added distilled water and phosphate buffer $\mathrm{pH} 7$, incubated $37^{\circ} \mathrm{C}$ for 15 mins. Finally, the solution was added alpha-amylase enzyme $(1 \mathrm{mg} / \mathrm{mL}$ in phosphate buffer $\mathrm{pH} 7$ ) and incubated for $30 \mathrm{mins}$ at $37^{\circ}$ C. An aliquot $(1 \mathrm{~mL})$ of the sample solution was transferred to a closed test tube containing $2 \mathrm{~mL}$ of DNS solution and heated in boiling water for 10 mins. All samples were measured in term of absorbance using spectrophotometer UV-Vis on $520 \mathrm{~nm}$. We used maltose as a standard solution for the determination of maltose content in starch samples and potato starch.

Starch digestibility was measured using the formula as follows:

Starch digetibility $=\frac{[\text { Maltose }] \text { sample }-[\text { Maltose }] \text { blank sample }}{[\text { Maltose }] \text { starch }-[\text { Maltose }] \text { blank starch }} \times 100$

\subsubsection{Amylose content}

A total of $0.1 \mathrm{~g}$ sample was weighed into $100 \mathrm{~mL}$ volumetric flask in triplicate. Then, $1 \mathrm{~mL}$ of $95 \%$ ethanol and $9 \mathrm{~mL}$ of $1 \mathrm{~N} \mathrm{NaOH}$ were added and boiled in waterbath for 10 mins. After cooling, distilled water was added to make the volume exactly $100 \mathrm{~mL}$. A blank solution was prepared following the previous steps except taking the sample to the volumetric flask. Then, 5 $\mathrm{mL}$ of sample solution was transferred to an empty 100 $\mathrm{mL}$ volumetric flask, then $70 \mathrm{~mL}$ distilled water, $1 \mathrm{~mL}$ of glacial acetic acid, and $2 \mathrm{~mL}$ of iodine solution were added. The volume was adjusted to exactly $100 \mathrm{~mL}$ with distilled water and left to stand for 20 mins. The absorbance was measured at $620 \mathrm{~nm}$ after setting zero with the blank solution. The value of the absorbance was calculated into the apparent amylose content using a standard calibration curve developed from potato amylose standard.

\subsubsection{Crystalization analysis using X-ray difraction}

The ground sample was adjusted to have 95\% moisture content and $25 \% \mathrm{w} / \mathrm{w}$ humidity. X-ray diffraction was operated at $600 \mathrm{~W}, 40 \mathrm{kV}, 15 \mathrm{~mA}$ and $\mathrm{CuK} \alpha 1(0.154 \mathrm{~nm})$. The analysis was conducted on 5 $30^{\circ}(2 \theta)$ for 16 mins and 14 seconds with $0.026^{\circ}$ per steps and the time per steps was $229.5 \mathrm{~s}$. The degree of cristallinity was determined using Origin Pro 8 software.

\subsubsection{Morphology using Scanning Electron Microscopy (SEM)}

The ground sample was put onto the specimen holder which has been coated with carbon tape. The coating process was conducted using sputter coater of quorum type Q150R ES with gold and sputter current 20 $\mathrm{mA}$ for $60 \mathrm{~s}$. Then, the coated sample was put into a chamber. Morphology of the sample was observed on the screen with 50,100, 500, 1000, 2000 and 5000 times of magnification. The results were captured using a camera with an SE detector (secondary electron), with a working distance of $8.0 \mathrm{~mm}$ and EHT $16.00 \mathrm{kV}$.

\section{Results and discussion}

3.1 Effect of modification on resistant starch (RS) content, digestibility of starch (DS) and amylose content

Based on the results of resistant starch content in Figure 1, native had the lowest resistant starch content that is $14.80 \pm 0.34 \%$ and control of $17.07 \pm 0.52 \%$. The levels of resistant starch to native tapioca starch were higher when compared with the resistant starch content of tapioca according to a study conducted by Pereira and Leonel (2014) that is equal from 0.56 to $1.1 \%$. High levels of resistant starch in this research can be caused by the method of resistant starch analysis which was used not through the high heating stage, so this process allows gelatinization process on starch, and the result obtained is quite large. Resistant starch content calculated based on total dietary fiber in unheated corn starch had higher RS $41.5 \pm 1.6 \%$ compared with preheated starch at $95^{\circ} \mathrm{C}$ temperature of $35.4 \pm 1.1 \%$ (Hasjim et al., 2010).

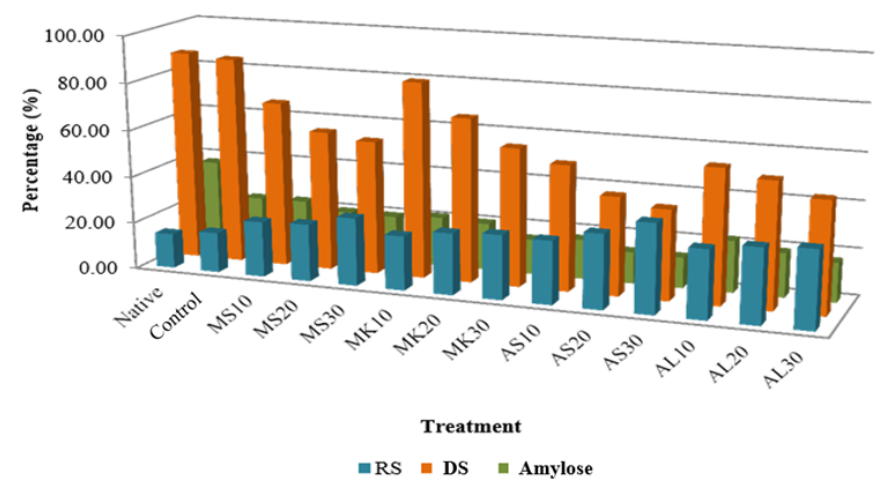

Figure 1. Resistant starch content (RS), digestibility of starch (DS) and amylose content of native and modified starch.

Resistant starch levels in the controls experienced a non-significant increase compared to native due to the retrograde process that allowed the establishment of RS3. AS30 produced the highest resistant starch content of $37.87 \pm 1.44 \%$, whereas the starch content was resistant to the treatment of stearic acid with concentrations of 10 and $20 \%$ respectively of $26.89 \pm 0.93 \%$ and $31.61 \pm 0.73 \%$. Modifications using palm oil (10-30\%) produce resistant starch of $23.65 \pm 0.99 \%, 24.42 \pm 0.84 \%$ and $28.88 \pm 1.50 \%$; MK (10-30\%) respectively $23.12 \pm 0.91 \%, 26.18 \pm 0.79 \%$, and $27.40 \pm 0.93 \%$, whereas $\mathrm{AL}$ treatments $(10-30 \%)$ were $29.12 \pm 1.04 \%, \quad 31.77 \pm 2.11 \%$ and $33.01 \pm 1.01 \%$, respectively. Multivariate analysis results show that the type of oil and fatty acids and concentrations used to cause significant differences. Hasjim et al. (2010) stated that there was an increase in the level of starch resistant to corn starch forming a complex compound with $10 \%$ 
(bk) of palmitic acid to $39.2 \pm 1.6 \%$ which was significantly different from the control. Different resistant starch content due to free fatty acids can form the amylose lipid complex, besides the length of the chain also affects the formation of lipid amylose complexes, stearic acid has a longer carbon chain $(\mathrm{C} 18$ : 0 ) compared to lauric acid (C12: 0$)$. The amount of resistant starch content is influenced by several factors such as the type of starch used, the type and concentration of lipids, also the condition for the formation of amylose lipid complex (Lau et al., 2016). The addition of rice bran oil can improve the resistant starch content in instant rice than control and result in higher slow digestion starch (Luangsangkul and Ritudomphol, 2018).

Based on the results of the analysis, decreased digestibility of starch oil and fatty acid starch concentration ranged from $18.97 \%$ to $50.99 \%$. Starch without modification had the highest starch digestibility value of $89.42 \pm 1.16 \%$, while the lowest starch digestibility is owned by $30 \%$ stearate acid-modified starch (AS30) of $38.42 \pm 1.52 \%$ which was significantly different from native and control. Modification with stearic acid at other concentrations, i.e. $10 \%$ and $20 \%$ had starch digestibility $51.98 \pm 0.37 \%$ and $41.90 \pm 0.60 \%$ significantly lower than native and control, respectively. The modified starch digestibility value by using lauric acid at concentrations of 10,20 and $30 \%$ was also significantly lower than that of native and control, respectively $\quad 57.10 \pm 0.18 \%, \quad 53.63 \pm 0.52 \% \quad$ and $47.56 \pm 1.11 \%$. Modification using palm oil produces starch digestibility of $70.44 \pm 0.21 \% ; 59.40 \pm 0.39 \%$ and $56.90 \pm 0.17 \%$, while modification with coconut oil resulted in starch digestibility of $83.30 \pm 0.44 \%$, $69.73 \pm 1.04 \%$ and $58.77 \pm 0.93 \%$, respectively. These results indicate that the process of starch modification with palm oil, coconut oil, stearic acid and lauric acid can significantly decrease starch digestibility. Fatty acid lower starch digestibility is greater than the treatment using oils. The decrease in starch digestibility also correlates with increased concentrations of oil or fatty acids added to the modification process. Ai et al. (2013) states that there is a decrease in enzymatic hydrolysis using PPA (porcine pancreatic $\alpha$-amylase) in tapioca starch to $66.4 \%$ in addition to $10 \%$ corn oil, $72.0 \%$ in $10 \%$ lauric acid addition, and $65.5 \%$ in acid addition stearate $10 \%$ after incubation for $120 \mathrm{~min}$. Farooq et al. (2017) also state that non-waxy rice with palm oil complexed have significantly increased the resistant starch content and decreased the rapidly digestible starch. The amylose-palm oil complex can block the enzymes to penetrate inside the starch granules that produce a form of a single helical $\mathrm{V}$-amylose structure and cause a high enthalpy change. Decreased starch digestibility also occurred in the millet that the content of rapidly digestible starch will be decreased with the addition of fatty acids. Besides that, polyunsaturated fatty acids have a low ability compared to monounsaturated fatty acids at the rate of starch digestion (Kawai et al., 2012; Annor et al., 2015).

The results of amylose content analysis are shown in Figure 1. Amylose content with the addition of oil and fatty acid resulted in lower amylose content than control. The lowest levels of amylose were found in AS30, which was $13.11 \pm 0.70 \%$, which was significantly different from amylose content in native starch and treatment control. The amylose content obtained at the treatment controls was $22.84 \pm 1.55 \%$, the results showed a significant decrease in the amylose levels in the native, due to the amylose leaching during the gelatinization process, allowing the formation of complex associations that could not form the complex with iodine in the retrogradation process (Wang et al., 2015). Decreased amylose levels in the treatment of adding oils and fatty acids are due in large part to amylose forming complex compounds with fatty acids so that the amylose available to form complex compounds with iodine is reduced. The results of the amylose content in Figure 1 show that the more oils or fatty acids added will decrease the amylose content which may form the compound of the complex with iodine. Bhatnagar and Hanna (1997) stated that iodine binding capacity at control was $3.68 \%$ and there was a decrease in lipid addition in the extrusion process such as stearic acid (2.18\%) and coconut oil (2.62\%). Decreased iodine binding capacity (IBC) or amylose ability to form complex compounds with iodine indicates the increased formation of lipid amylose complexes. The treatment of fatty acids will reduce the amount of amylose because fatty acids more easily form complex compounds with amylose (Tufvesson et al., 2003).

\subsection{Diffractogram of resistant starch}

The formation of lipid amylose complexes can be observed using X-Ray diffraction at an angle of $2 \theta$ of about $7.5^{\circ}, 12.7^{\circ}$, and $19.9^{\circ}$ (Cheetam and Tao, 1998). The result of the diffractogram in Figure 2 shows that there is no crystalline peak in the control, MS30 and MK30. Native samples have a maximum peak at $15^{\circ}$, $18^{\circ}$ and $24^{\circ}$, the crystals formed are crystals A. This is because the amount of amylose-lipid complex is too low, so it cannot be read by X-Ray like waxy rice samples (Farooq et al., 2017). Bhatnagar and Hanna (1994) state that native starch exhibits a maximum peak at $15.1^{\circ}$, $16.4^{\circ}, 17.5^{\circ}, 18.7^{\circ}$ and $22.6^{\circ}$ approaching the type A crystalline pattern, whereas type B crystals have a maximum peak at $17^{\circ}$ and type $\mathrm{C}$ at $15^{\circ}, 17^{\circ}, 23^{\circ}, 31^{\circ}$ and $38^{\circ}$ (Marimuthu et al., 2013). Based on the results of the diffractogram analysis (Figure 2), AS30 indicated a 
peak at $7.5^{\circ}, 11.5^{\circ}, 22^{\circ}$ and $24^{\circ}$. Peak at $7.5^{\circ}$ indicates the formation of a lipid amylose complex, with AL30 having a maximum peak at $9.9^{\circ}, 13.2^{\circ}, 21^{\circ}, 22^{\circ}$ and $24^{\circ}$, but no lipid amylose complexes at $7.5^{\circ}, 12.7^{\circ}$ and $19.9^{\circ}$ peaks. Peak $21^{\circ}, 22^{\circ}$ and $24^{\circ}$ are due to the reflection results of pure crystals of fatty acids that do not form the association with starch as reported by Fanta et al. (1999) that peak at $21.4^{\circ}$ and $23.8^{\circ}$ increases with the increasing length of fatty acids reflecting pure crystalline from fatty acids that do not form complexes with amylose.
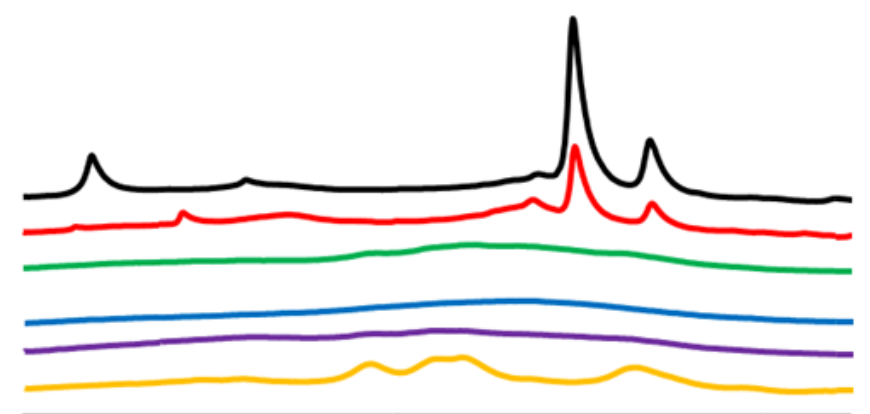

ํㅜㅇำ

- Native —Control —MS30 - MK30 - AS30 - AL30

Figure 2. The result of diffractogram using X-Ray Diffraction at angle $2 \theta$

\subsection{Gelatinization of modified tapioca starch}

Based on the analysis result (Figure 3), the control had the highest peak viscosity (PV) which was equal to $6319 \mathrm{cP}$. The lowest breakdown in AS30 is $153 \mathrm{cP}$, low breakdown indicates resistance to heating. The highest HPV is in control and AL30 indicates high eating quality and low cooking loss (Bhattacharya et al., 1999). In addition, AS30 had the lowest setback that showed resistance to the retrograde process (Kusnandar, 2011). The controls have the fastest peak time of 4.33 mins while the AS30 has the longest peak time of 12.07 mins. Ai et al. (2013) states that the compound amylose lipid can increase the temperature of gelatinization, it is in accordance with the analysis results on AS30 and AL30 samples that show the temperature of gelatinization on AS30 of $90.25^{\circ} \mathrm{C}$ and $\mathrm{AL} 30$ of $92.25^{\circ} \mathrm{C}$ greater than native that is equal to $69.6^{\circ} \mathrm{C}$. The addition of oil showed different results i.e reducing gelatinization temperature by $50.25^{\circ} \mathrm{C}$ at $\mathrm{MS} 30$ and $50.3^{\circ} \mathrm{C}$ at MK30. The formation of the amylose-lipid complex in bread occurs in temperatures above $90^{\circ} \mathrm{C}$. This temperature allows the formation of well-defined crystalline structures (Lau et al., 2016).

Based on Schoch and Maywald (1968), there are 4 types of starch gelatinization profiles including type A, type $\mathrm{B}$, type $\mathrm{C}$ and type $\mathrm{D}$. Type $\mathrm{A}$ is starch with high peak viscosity but is not resistant to heating so it is easy to decrease its viscosity. Type $B$ has the same characteristics as type A but has a lower peak viscosity and lower decreased quantity. Type $\mathrm{C}$ is a starchresistant starch, subject to limited development shown in the absence of peak viscosity and breakdown. Type D is starch with limited inflowing power is shown by a low viscosity profile. Based on the classification of native starch, control, MS30 and MK30 belong to type A, while AS30 and AL30 were C type starch.

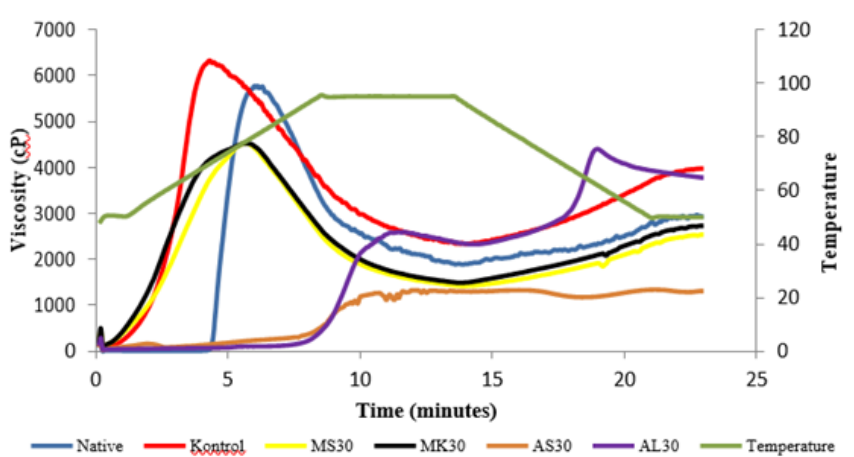

Figure 3. Profile of modified tapioca starch gelatinization using Rapid Visco Analyzer (RVA)

\subsection{Modified starch morphology}

The granular morphology using SEM instrument was performed on native starch, control, and some samples yielding the highest resistant starch content in each treatment i.e. MS30, MK30, AS30 and AL30. The result of observation using SEM in Figure 4A shows that
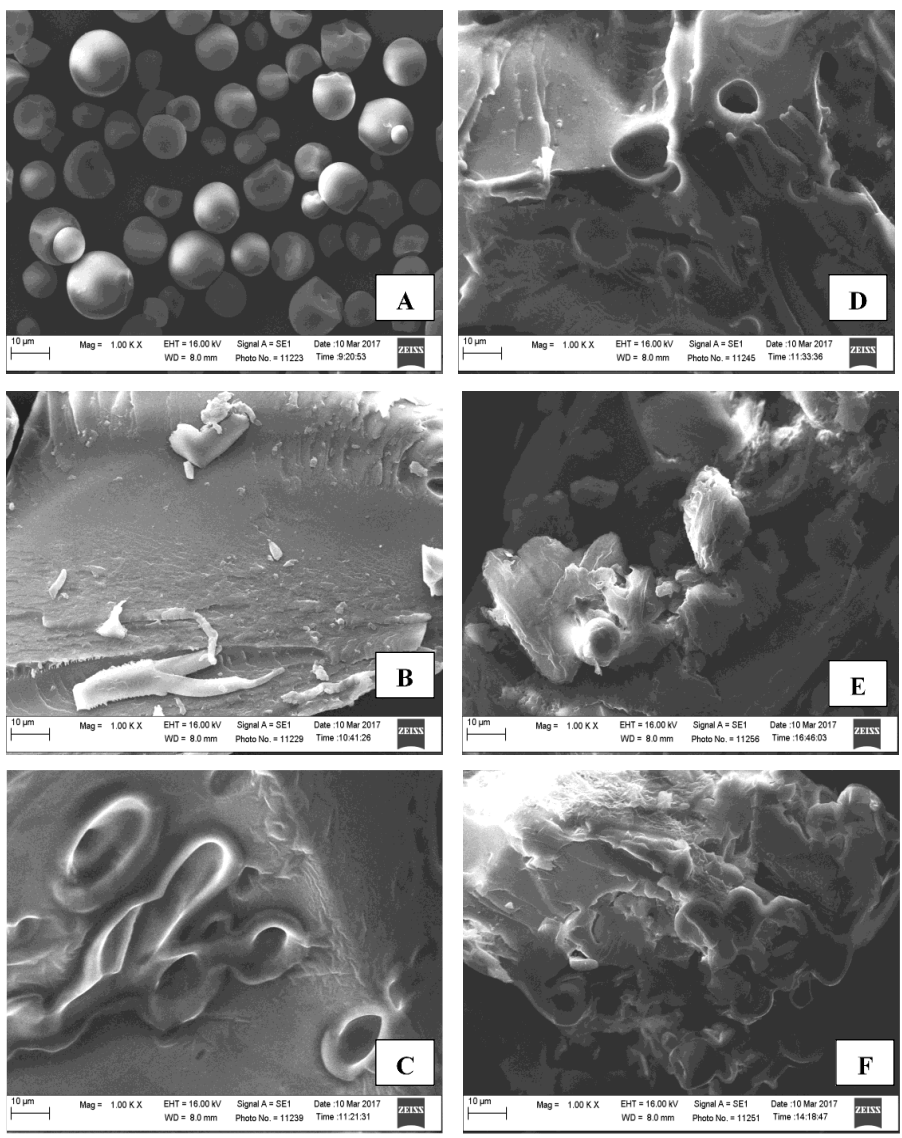

Figure 4. The morphological results of cassava starch granules interfere with native (A), control (B), 30\% palm oil (C), 30\% coconut oil (D), stearic acid 30\% (E) and 30\% lauric acid (F) at $1000 x$ magnification 
native starch had intact round granule starch. Figure 4B (control) shows the starch granules have been completely gelatinized. Figure 4C (M30), Figure 4E (AS30) and Figure 4F (AL30) indicate there were some broken starch granules, having swelling marked by increasing the size of the granule and most of the other clumpshaped granules showed that starch had undergone gelatinization process, but there are still some intact granules. The intact granules indicate an imperfect gelatinization process, due to the obstruction of water in the presence of oil or fatty acids (Gelders et al., 2006).

\section{Conclusion}

Modification of tapioca starch through the gelatinization process with the addition of palm oil, coconut oil, strearic acid and lauric acid can decrease starch digestibility, increase levels of resistant starch and lower amylose levels. Different types of oils or fatty acids and their concentration have an effect on the increase of starch resistance and decreasing starch digestibility and amylose significantly. The analysis using X-Ray diffraction showed AS30 had a peak at $7.5^{\circ}, 22^{\circ}$ and $24^{\circ}$. Peak $7.5^{\circ}$ was a lipid amylose complex whereas AL30 had a maximum peak at $21^{\circ}, 22^{\circ}$ and $24^{\circ}$, and other treatments did not show peak lipid amylose complexes at $7.5^{\circ}, 12.7^{\circ}$ and $19.9^{\circ}$. The profile of starch gelatinization using Rapid Visco Analyzer showed that the addition of fatty acid can decrease the value of breakdown, setback, and peak viscosity. AS30 had the lowest breakdown and setback of $153 \mathrm{cP}$ and 135 $\mathrm{cP}$ and peak viscosity of $1329 \mathrm{cP}$. In addition, the addition of fatty acids was able to increase the gelatinization temperature of $90.25^{\circ} \mathrm{C}$ at $\mathrm{AS} 30$ and $92.25^{\circ} \mathrm{C}$ at AL30. The morphological observations of modified starch contained some intact starch granules, some of which had swelling characterized by increasing granular size.

\section{Conflict of interest}

The authors declare no conflict of interest.

\section{Acknowledgement}

We are grateful to PT Indofood Sukses Makmur Tbk for funding this research by Indofood Riset Nugraha (IRN) Grant Program.

\section{References}

Ai, Y., Hasjim, J. and Jane, J.L. (2013). Effect of lipids on enzymatic hydrolysis and physical properties of starch. Carbohydrate Polymer, 92(1), 120-127. https://doi.org/10.1016/j.carbpol.2012.08.092

Aliasson, A.C. and Krog, N. (1985). Physical properties of Amylose-Monoglyceride Complexes. Journal of Cereal Science, 3(3), 239-248. https:// doi.org/10.1016/S0733-5210(85)80017-5

Annor, G.A., Marcone, M., Corredig, M., Bertoft, E. and Seetharaman, K. (2015). Effects of the amount and type of fatty acids present in millets on their in vitro starch digestibility and expected glycemic index (eGI). Journal of Cereal Science, 64, 76-81. https:// doi.org/10.1016/j.jcs.2015.05.004

Bhatnagar, S. and Hanna, M.A. (1994). Amylose lipid complex formation during single- screw extrusion of various corn starches. Cereal Chemistry, 71(6), 582587.

Bhatnagar, S. and Hanna, M.A. (1997). Modification of microstructure of starch extruded with selected lipids. Starch/Starke, 49(1), 12-20. https:// doi.org/10.1002/star.19970490105

Bhattacharya, M., Zee, S.Y. and Corke H (1999). Physicochemical properties related to quality of rice noodles. Cereal Chemistry, 76(6), 861-867. https:// doi.org/10.1094/CCHEM.1999.76.6.861

Birt, D.F., Bolyston, T., Hendrich, S., Jane, J.L., Holis, J., Li L., McCelland, J., Moore, S., Phillips, G.J., Rowling, M., Schalinsko, K.M., Scott, M.P. and Whitley, E.M. (2013). Resistant starch: Promise for improving human health. Advances in Nutrition, 4 (6), 587-601. https://doi.org/10.3945/an.113.004325

Carolina. (2009). How to calibrate the opportunities of Sampeu Manggu (Manihot esculenta Linn) innovation. Indonesia: LIPI.

Cheetam, N.W.H. and Tao, L. (1998). Variation in crystalline type with amylose content. Carbohydrate Polymer, 36(4), 277-284. https://doi.org/10.1016/ S0144-8617(98)00007-1

Fanta, G.F., Shogren, R.L. and Saleh, J.H. (1999). Steam jet cooking of high-amylose starch-fatty acid mixtures. An investigation of complex formation. Carbohydrate Polymer, 38(1), 1-6. https:// doi.org/10.1016/S0144-8617(98)00104-0

Faridah, D.N., Purnamasari, N. and Suryaatmaja B.S.L. (2019). Physicochemical Characteristics of Modified Daluga Flour (Cyrtosperma Merkusii. (Hassk.) Schott) by Lactic Acid Bacteria Fermentation and Heat Moisture Treatment. Jurnal Aplikasi Teknologi Pangan, 8(3), 94-99. https://doi.org/10.17728/ jatp. 4203

Farooq, A.M., Dhital, S., Li, C., Zhang, B. and Huang, Q. (2017). Effects of palm oil on structural and in vitro digestion properties of cooked rice starches. International Journal of Biological Macromolecules, 107(Part A), 1080-1085. https://doi.org/10.1016/ j.ijbiomac.2017.09.089 
Gelders, G.G., Goesart, H. and Delcour, J.A. (2006). Amylose-Lipid Complexes as Controlled Lipid Release Agents during Starch Gelatinization and Pasting. Journal of Agricultural and Food Chemistry, 54(4), 1493-1499. https:// doi.org/10.1021/jf051743c

Hartati and Hartati, N.S., (2019). Potential of yields and starch production from several local cassava genotypes. Bioscience, 3(1), 31-39. https:// doi.org/10.24036/0201931103944-0-00

Hasjim, J., Lee, S.O., Hendrich, S., Setiawan, S., Ai, Y. and Jane, J.L. (2010). Characterization of a novel resistant starch and its effects on postprandial plasma glucose and insulin responses. Cereal Chemistry, 87 (4), 257-262. https://doi.org/10.1094/CCHEM-87-40257

Jane, J.L. and Robyt, J.F. (1984). Structure studies of amylose- $v$ complexes and retrograded amylose by action of alpha amylases and a new method for preparing amylodextrins. Carbohydrate Research, 132(1), 105-118. https://doi.org/10.1016/0008-6215 (84)85068-5

Kawai, K., Takato, S., Sasaki, T. and Kajiwara, K. (2012). Complex formation, thermal properties, and in-vitro digestibility of gelatinized potato starchfatty acid mixtures. Food Hydrocolloids, 27(1), 228234. https://doi.org/10.1016/j.foodhyd.2011.07.003

Kusnandar, F. (2011). Food Chemistry: Macromolecular compound. Indonesia: Dian Rakyat.

Lau, E., Zhou, W. and Henry, C.J. (2016). Effect of fat type in baked bread on amylose-lipid complex formation and glycaemic response. British Journal of Nutrition, 115(12), 2122-2129. https:// doi.org/10.1017/S0007114516001458

Lingga, P.B., Sarwono, F., Rahadi, P.C., Raharja, J.J., Afistini, Rini, W. and Apriadi, W.H. (1986). Planting tubers. Indonesia: Penebar Swadaya.

Luangsangkul, N. and Ritudomphol, O. (2018). Effect of oil addition on in vitro starch digestibility and physicochemical properties of instant rice. International Journal of Agricultural Technology, 14 (7), 1399-1412.

Marimuthu, M., Uma, S. and Gurumoorthi, P. (2013). Xray diffraction and starch analysis of nano-sized seed powder of velvet bean (Mucuna pruriens). Nano Biomedicine and Engineering, 5(3), 121 - 126.

Ministry of Agriculture. (2016). Agricultural Commodity Outlook for Cassava Food Crop Sub Sector. Indonesia: Center for Agriculture Data and Information Systems Ministry of Agriculture.

Obiro, W.C., Ray, S.S. and Emmambux, M.N. (2012). V -amylose structural characteristics, methods of preparation, significance, and potential applications. Food Reviews International, 28(4), 412-438. https:// doi.org/10.1080/87559129.2012.660718

Pereira, B.L.B. and Leonel, M. (2014). Resistant starch in cassava products. Journal of Food Science and Technology, 34(2), 298-302. https://doi.org/10.1590/ fst.2014.0039

Schoch, T.J. and Maywald, E.C. (1968). Preparation and properties of various legume starches. Cereal Chemistry, 45, 564-573.

Tufvesson, F., Wahlgren, M. and Eliasson, A.C. (2003). Formation of amylose-lipid complexes and effect of temperature treatment part 2 Fatty acid. Starch/ Starke, 55(3-4), 138-149. https://doi.org/10.1002/ star.200390028

Wang, S., Li, C., Copela, L. and Niu, Q. (2015). Starch Retrogradation: A comprehensive review. Comprehensive Reviews in Food Science and Food Safety, 14(5), 568-585. https://doi.org/10.1111/15414337.12143 